OPEN ACCESS

Edited by:

Olayinka Olabode Ogunleye, Lagos State University, Nigeria

Reviewed by:

Raja Ahsan Aftab,

Taylor's University, Malaysia

Tanja Mueller,

University of Strathclyde,

United Kingdom

*Correspondence:

Yu Fang

yufang@mail.xjtu.edu.cn

Specialty section: This article was submitted to Pharmaceutical Medicine and

Outcomes Research,

a section of the journal

Frontiers in Pharmacology.

Received: 14 August 2020 Accepted: 04 December 2020

Published: 25 January 2021

Citation:

Saeed A, Saeed F, Saeed H, Saleem Z, Yang $C$, Chang J, Jiang $M$, Zhao $M$, Saqlain M, Ji W, Aziz MM, Lambojon K, Gillani AH, Hayat K, Gul S, Fang Y and Babar Z-U-D (2021) Access to

Essential Cardiovascular Medicines in Pakistan: A National Survey on the Availability, Price, and Affordability, Using WHO/HAl Methodology. Front. Pharmacol. 11:595008. doi: 10.3389/fphar.2020.595008

\section{Access to Essential Cardiovascular Medicines in Pakistan: A National Survey on the Availability, Price, and Affordability, Using WHO/HAI Methodology}

\begin{abstract}
Amna Saeed 1,2,3,4 Faria Saeed ${ }^{5}$, Hamid Saeed ${ }^{6}$, Zikria Saleem ${ }^{4}$, Caijun Yang ${ }^{1,2,3}$, Jie Chang ${ }^{1,2,3}$, Minghuan Jiang ${ }^{1,2,3}$, Mingyue Zhao ${ }^{1,2,3}$, Muhammad Saqlain ${ }^{7}$, Wenjing $\mathrm{Ji}^{1,2,3}$ Muhammad Majid Aziz ${ }^{1,2,3}$, Krizzia Lambojon ${ }^{1,2,3}$, Ali Hassan Gillani ${ }^{1,2,3}$, Khezar Hayat ${ }^{1,2,3,8}$, Sabiha Gul ${ }^{9}$, Yu Fang ${ }^{1,2,3 *}$ and Zaheer-Ud-Din Babar ${ }^{10}$

${ }^{1}$ Department of Pharmacy Administration and Clinical Pharmacy, School of Pharmacy, Xi'an Jiaotong University, Shaanxi, China, ${ }^{2}$ Center for Drug Safety and Policy Research, Xi'an Jiaotong University, Shaanxi, China, ${ }^{3}$ Shaanxi Centre for Health Reform and Development Research, Shaanxi, China, ${ }^{4}$ Faculty of Pharmacy, the University of Lahore, Lahore, Pakistan, ${ }^{5}$ Allama lqbal Medical College, Lahore, Pakistan, ${ }^{6}$ Department of Pharmaceutics, University College of Pharmacy, University of the Punjab, Lahore, Pakistan, ${ }^{7}$ Department of Pharmacy, Quaid e Azam University, Islamabad, Pakistan, ${ }^{8}$ Institute of Pharmaceutical Sciences, University of Veterinary and Animal Sciences, Lahore, Pakistan, ${ }^{9}$ Department of Pharmacology, Faculty of Pharmacy, Hamdard University, Karachi, Pakistan, ${ }^{10}$ Department of Pharmacy, School of Applied Sciences, University of Huddersfield, Huddersfield, United Kingdom
\end{abstract}

Objective: This national survey was aimed at measuring the access to cardiovascular disease (CVD) medicines in terms of their availability, price, and affordability in Pakistan. This was done by using the standard WHO/Health Action International (HAl) methodology.

Methods: The price and availability data for $18 \mathrm{CVD}$ medicines were collected from public sector hospitals $(n=40)$ and private sector retail pharmacies $(n=40)$ in eight cities of Pakistan. The outcome measures were availability (calculated as percentage of health facilities stocked with listed medicines), medicine price to the international reference price ratio (i.e., median price ratio (MPR)), and affordability (calculated as number of days' wages (NDWs) of the lowest paid unskilled government worker required to afford one-month treatment of a chronic disease). The affordability of standard treatment in Pakistan with four CVD drugs was compared with data from six other low and middle income countries (LMICs) using HAl database.

Findings: The mean percent availability of CVD medicines was significantly low $(p<0.001)$ in the public sector as compared to the private sector, that is, $25.5 \%$ vs. $54.6 \%$ for originator brands (OBs) and $30.4 \%$ vs. $34.9 \%$ for lowest price generics (LPGs), respectively. For all OBs and LPGs, the inflation-adjusted mean MPR was 2.72 and 1, respectively. CVD medicines were found to be unaffordable with average NDWs of 6.4 and 2.2 for OBs and LPGs, respectively, that is, NDWs of more than 1. In international comparison with countries such as Sudan, Lebanon, Egypt, India, Afghanistan, and China, the affordability of standard treatment with selected CVD medicines (atenolol, amlodipine, captopril, and simvastatin) in Pakistan was found to be low. Overall, all four 
OBs and three out of four LPGs of selected CVD drugs were found unaffordable in Pakistan.

Conclusion: This data indicated that the availability of selected CVD medicines was low in both public and private sector medicine outlets. Both OBs and LPGs were found unaffordable in the private sector, necessitating the redressal of pricing policies, structuring, and their implementation.

Keywords: cardiovascular drugs, access to medicines, medicines policy, essential medicines, non-communicable diseases

\section{INTRODUCTION}

Globally, non-communicable diseases (NCDs) have emerged as a leading cause of mortality. These account for approximately 41 million people annually, which is equivalent to $71 \%$ of all the deaths worldwide (WHO, 2011). More than $85 \%$ of these deaths occur in low and middle income countries (LMICs). With population of 197 million, Pakistan is the fifth most populous country in the world, and about half of its population is suffering from one or more chronic diseases (Jafar et al., 2013; Population, Pakistan Bureau of Statistics, 2020). In 2013, Jaffer et al. estimated that in Pakistan, from 2010 to 2025, almost 3.87 million people will die due to NCDs, such as cardiovascular diseases (CVDs), cancers, and chronic respiratory diseases. The authors also projected that the economic burden associated with NCD deaths will be between $\$ 152$ million and $\$ 296$ million between 2010 and 2025 (Jafar et al., 2013). In Pakistan, the total health expenditure, as a percentage of the GDP, was 1.1\% in 2018-2019. The public sector bears $32 \%$ of the health expenditures, while $64 \%$ is borne by patient's out of pocket (OOP) payments that may lead to catastrophic consequences for the families (Quick et al., 2002; Hsu et al., 2018; Khan, 2019; Ministry of Finance, Government of Pakistan, 2020). In public sector hospitals, the medicines are provided free of charge, while in private sector hospitals and retail pharmacies the patients have to pay out of pocket to obtain medicines.

Among NCDs, cardiovascular diseases (CVDs) pose a major threat with annual casualties of around 17.9 million (Lozano et al., 2012). According to the World Health Organization (WHO), CVDs include hypertension (HTN), coronary heart disease, cerebrovascular disease (stroke), peripheral vascular disease, heart failure, rheumatic heart disease, congenital heart disease, and cardiomyopathies (WHO, 2020a). According to the global burden of diseases data, CVDs are among the top ten leading causes of deaths in Pakistan with ischemic heart disease (IHD) leading the numbers (causing $8 \%$ of all deaths) (WHO, 2011; Lozano et al., 2012; Murray and Lopez, 2017).

The WHO recommends multi-drug therapy for the treatment and prevention of CVDs in patients with $\geq 30 \%$ risk of developing stroke or heart attack within ten years. These therapies include blood pressure (BP) lowering medicines, anti-hyperlipidemic (HLD) medicines, blood glucose control for diabetic patients, and anti-platelet drugs for secondary prevention of myocardial infarction. Despite strong clinical evidence about the effectiveness of medicines in preventing and controlling CVDs, disparity exists between the patients requiring treatment and those having actual access to these medicines (Wirtz et al., 2016). Moreover, a longterm therapy is required for NCDs, which incurs significant health care cost. For example, in 2010, Bloom et al. estimated the direct medical costs of 5 groups of NCDs (CVDs, diabetes, cancer, chronic respiratory diseases, and neurological disorders) to be US $\$ 3,705$ billion, globally (The Global Economic Burden of Non-Communicable Diseases, World Economic Forum). A substantial portion of such medical costs of NCDs comprises medicines, making it obligatory to make the medicines affordable and accessible for patients (Mendis et al., 2005). Therefore, a Global Action Plan has been developed by the WHO aiming for $80 \%$ availability of affordable essential medicines for NCDs in both public and private health facilities (Beran et al., 2014). Moreover, "access to essential medicines" is a fundamental human right, and it has officially been declared as a pledge under Millennium Development Goal (MDG) 8, suggesting that the provision of affordable, high quality, and appropriate essential medicines is one of the major components of functioning health systems, which however remains questionable in LMICs (Sachs and McArthur, 2005; Zaidi et al., 2013). Besides, National Health Vision 2016-2025 was developed and aligned with Sustainable Development Goals (SDGs) to attain resilient and responsive health system. The notable institutional arrangement for health-related SDGs entails several vertical programs running at federal and provincial levels, such as malaria control, TB control, maternal and child health program, and HIV/AIDS control programs, along with the provision of medical staff, equipment, and essential medicines in all hospitals. However, the availability, affordability, accessibility, acceptability, and quality of medicines are the various key requisites to recuperate the health system in line with SDGs (Penchansky and Thomas, 1981; Pakistan Country Report-Sustainable Development Goals, 2017).

WHO-PREMISE (Prevention of Recurrences of Myocardial Infarction and Stroke) study was conducted, predominantly in LMICs. The study assesses the use of medicines in the secondary prevention of CVDs. The study analyzed whether the patients received the prescribed therapy in 10 LMICs. The data revealed that only $48 \%$ of chronic heart disease (CHD) patients received beta blockers, $40 \%$ of $\mathrm{CHD}$ patients and $38 \%$ of stroke patients received $\mathrm{ACE}$ inhibitors, and $30 \%$ of $\mathrm{CHD}$ patients and $14 \%$ of stroke patients could receive statins (Mendis et al., 2005). Another study called WHO-PURE (Prospective Urban Rural Epidemiology) was conducted to estimate the availability and 
affordability of four therapeutic classes of CVD medicines in 18 countries. The study findings suggested that the availability of CVD medicines was only $62 \%$ in urban community (UC) and $37 \%$ in rural community (RC) in lower middle income countries, and it was $80 \%$ in UC and $73 \%$ in RC in upper middle income countries, and it decreased to only $25 \%$ in UC and $3 \%$ in RC in low income countries. The treatment with CVD medicines was unaffordable to $25 \%, 33 \%$, and $60 \%$ of the households in the upper middle income, lower middle income, and low income countries, respectively (Khatib et al., 2016).

Studies, conducted in Ghana, Brazil, and Mexico, reported that high medicine prices are major contributors that may lead to reduced patient adherence to medication therapy and hence can compromise the access to CVD medicines (Calvo-Vargas et al., 1998; Buabeng et al., 2004; De Tole̊do Nóbrega et al., 2007). However, many of these studies did not use standardized methodologies. In this context, WHO and Health Action International (HAI) developed a standardized methodology, and more than 100 surveys have been conducted by using this methodology. This is a valid method to measure the access to medicines in terms of availability and affordability and can also be used for a reliable comparison of access to medicines among different countries (WHO, 2015). In 2010, a secondary data analysis of WHO/HAI methodology surveys assessed the access to CVD medicines in 36 countries, and the availability was found to be low. It was observed to be $26 \%$ in public sector and $57 \%$ in private sector medicine outlets for a number of medicines. It was also reported that the treatment for CVD was not affordable in many countries, especially LMICs (van Mourik et al., 2010). Moreover, WHOs' Global Action Plan has set a major goal to achieve $50 \%$ use of recommended CVD medications worldwide by 2025. Thus, widespread and capacious availability and affordability of these medicines are necessary to attain this goal (WHO, 2013).

About fifteen years ago, the first WHO/HAI survey of Pakistan was conducted by Kiani et al. (2006) to evaluate the access of 29 essential medicines and reported poor availability and affordability of these medicines in the region. After this, the WHO/HAI methodology was improved and updated in 2008 (WHO, 2015). In 2016-2017, another WHO/HAI survey (following updated methodology) to evaluate the access to 50 essential medicines in general was conducted in Lahore division in Pakistan (Saeed et al., 2019). A subsequent survey was performed by Saeed et al. in 2019, using the same 50 drugs to evaluate the impact of new National Drug Pricing Policy (NDPP) 2018 on the access to medicines and compare their prices, availability, and affordability in both years, that is, 2017 and 2019. The authors reported a significant increase in drug prices with slight improvements in the availability of these drugs, yet considerably poor in both years, that is, far less than $80 \%$ (Saeed et al., 2019). However, these surveys were conducted in only one administrative unit of Pakistan, that is, Lahore division, and the results could not be generalized to the whole of Pakistan. Besides, from Pakistan, to our knowledge, not a single study has been conducted focusing on a specific class of drugs or diseases; that is, only a few drugs were included from each category.
So, this is the first national scale study in Pakistan to measure the access to CVD medicines in the country. Since this study covers the major regions of Pakistan, it would also give an insight into the regional disparities in access to CVD medicines. In this context, the objective of this study was to evaluate the availability, price, and affordability of CVD medicines in Pakistan and to compare the local situation with other LMICs using standard WHO/HAI methodology.

\section{METHODOLOGY}

\section{Study Outline}

A cross-sectional survey was conducted by using standard WHO/ HAI methodology. The data on 18 selected CVD medicines' availability, price, and affordability were collected from September to December, in 2019. A total of eight regions/cities were selected for the survey, that is, Islamabad (federal capital), Lahore (Punjab province), Bahawalpur (Punjab province), Peshawar (Khyber Pakhtun Khwa (KPK) province), Abbottabad (KPK province), Karachi (Sindh province), Quetta (Baluchistan province), and Muzaffarabad (Azad Jammu and Kashmir (AJK) autonomous region). Thus, all four provinces of Pakistan, one of the two autonomous regions (i.e., AKJ), and the federal capital were included in the survey (see Table 1). Trained data collectors gathered the data on availability and patient prices of all selected medicines from both public sector hospitals and private retail pharmacies.

\section{Sampling Plan}

The WHO/HAI methodology (details explained in the WHO/ HAI survey manual) recommends to survey a minimum of six survey areas in a survey region (WHO, 2015). In this study, we increased the number of survey areas to eight, as Pakistan is a large country in terms of population. With the population of 197 million, Pakistan is the fifth most populous country in the world and belongs to the group of lower middle income countries, according to the World Bank (World Bank Country and Lending Groups, World Bank Data Help Desk, 2020). It consists of four provinces (Punjab, KPK, Sindh, and Baluchistan) and two autonomous regions (Gilgit-Baltistan and AJK). All provincial capitals and capital of an autonomous region along with federal capital were included in the study to make a representative sample of the whole country (see Table 1). Other than the capital city in each province, one additional city was included from the Punjab and KPK provinces.

As required by the standard WHO/HAI methodology, one biggest public sector hospital was selected as a survey anchor in each survey area. Four public sector hospitals within $3 \mathrm{~km}$ range from the survey anchor were randomly selected in each survey area, making a total of five public sector hospitals in each city/ survey area. One private retail pharmacy was selected, within $5 \mathrm{~km}$ range of each public sector facility, making a total of five retail pharmacies in a survey area (see Supplementary Figure S1). In total, 80 medicine outlets were surveyed including 40 public sector hospitals and 40 retail pharmacies. 
TABLE 1 | Number of outlets samples and geographical location of participating cities.

\begin{tabular}{|c|c|c|c|c|c|c|}
\hline \multirow[t]{2}{*}{ Province } & \multirow{2}{*}{$\begin{array}{l}\text { Provincial/regional } \\
\text { population }\end{array}$} & \multirow[t]{2}{*}{ City surveyed } & \multicolumn{4}{|c|}{ Number of facilities in each city } \\
\hline & & & $\begin{array}{l}\text { Tertiary care } \\
\text { hospitals }\end{array}$ & $\begin{array}{l}\text { Secondary care } \\
\text { hospitals }\end{array}$ & $\begin{array}{c}\text { Primary } \\
\text { healthcare centers }\end{array}$ & $\begin{array}{c}\text { Private retail } \\
\text { pharmacy }\end{array}$ \\
\hline Federal capital & 1.015 million & Islamabad & 2 & 2 & 1 & 5 \\
\hline \multirow[t]{2}{*}{ Punjab } & 110 million & $\begin{array}{l}\text { Lahore (provincial } \\
\text { capital) }\end{array}$ & 3 & 2 & 0 & 5 \\
\hline & & Bahawalpur & 1 & 3 & 2 & 5 \\
\hline \multirow[t]{2}{*}{ Khyber Phakhtoon Khuwa (KPK) } & 35.53 million & Abbottabad & 1 & 2 & 2 & 5 \\
\hline & & $\begin{array}{l}\text { Peshawar (provincial } \\
\text { capital) }\end{array}$ & 1 & 2 & 2 & 5 \\
\hline Sindh & 47.9 million & $\begin{array}{l}\text { Karachi (provincial } \\
\text { capital) }\end{array}$ & 2 & 3 & 0 & 5 \\
\hline Baluchistan & 12.34 million & $\begin{array}{l}\text { Quetta (provincial } \\
\text { capital) }\end{array}$ & 1 & 3 & 1 & 5 \\
\hline $\begin{array}{l}\text { Azad Jammu and Kashmir (AJK) } \\
\text { (special administrative region) }\end{array}$ & 4.45 million & Muzaffarabad & 1 & 2 & 2 & 5 \\
\hline
\end{tabular}

TABLE 2 | List of medicines for survey.

Medicine with strength and dosage form
Part of NEML (yes/no)

Furosemide $40 \mathrm{mg}$ cap/tab Atenolol $50 \mathrm{mg}$ tab

Simvastatin $20 \mathrm{mg}$ cap/tab Amlodipine $5 \mathrm{mg}$ tab

Captopril 25 mg cap/tab

Enalapril $5 \mathrm{mg}$ tab

Nifedipine Retard $20 \mathrm{mg}$ tab

Atorvastatin $20 \mathrm{mg}$ cap/tab

Hydrochlorothiazide $25 \mathrm{mg}$

cap/tab

Digoxin $0.25 \mathrm{mg}$ tab

Losartan 50 mg cap/tab

Propranolol $40 \mathrm{mg}$ tab

Methyldopa $250 \mathrm{mg}$ tab Amiodarone $200 \mathrm{mg}$ tab Bisoprolol 5 mg cap/tab Lovastatin $20 \mathrm{mg}$ tab

Spironolactone $100 \mathrm{mg}$ tab

Acetylsalicylic acid 75 mg tab

\section{Yes}

Yes

Yes

Yes

No

Yes

No

No

Yes

Yes

Yes

Yes

Yes

Yes

Yes

No

Yes

Yes
Indication/s for use

Hypertension and fluid retention in heart failure

Hypertension

Hypercholesterolemia/prevention of CVDs

Hypertension

Hypertension and congestive heart failure

Hypertension and prevention of symptomatic heart failure

Hypertension and prophylaxis of chronic stable angina pectoris

Hypercholesterolemia/prevention of CVDs

Hypertension

Congestive heart failure

Hypertension and stroke prevention

Hypertension, management of angina pectoris, and control of most

forms of cardiac arrhythmias

Hypertension

Arrhythmias

Hypertension and stable chronic angina

Hypercholesterolemia/prevention of CVDs

Congestive heart failure

Secondary prevention of thrombotic cerebrovascular or cardiovascular disease
Pharmacological class

Loop diuretic

Beta blocker

HMG-CoA reductase inhibitors

Calcium channel blocker

ACE inhibitor

ACE inhibitor

Calcium channel blocker

Lipid modifying agent

Diuretic

Cardiac glycoside

Angiotensin II receptor antagonists

Beta blocker

Adrenergic receptor agonist

Antiarrhythmic drug

Beta blocker

HMG-CoA reductase inhibitors

Potassium-sparing agents

Antiplatelet drug

NEML, National Essential Medicines List.

\section{Selection of Medicines}

In this survey, 18 medicines used to treat CVDs were selected that included medicines from both global core list $(n=3)$ and supplementary list $(\mathrm{n}=15)$. The global core list of medicines is provided in the $\mathrm{WHO} / \mathrm{HAI}$ manual. It contains the essential medicines which are preferentially used while conducting all such surveys, which helps in performing international comparisons. According to the standard WHO/HAI methodology, each country can select supplementary medicines for survey on the basis of their significance and relevance in treating national healthcare problems (WHO, 2015). In this study, the supplementary medicines were carefully selected following the recommendations of $\mathrm{WHO} / \mathrm{HAI}$ advisor (author $\mathrm{ZB}$ ) and a national advisory board that consisted of physicians, pharmacists, drug procurement officers, and academicians. The National Essential Medicines List 2018 (NEML) was also consulted while selecting the medicines (Drug Regulatory Autority of Pakistan, 2018b). In this respect, 14 out of 18 selected medicines were also part of NEML 2018 (see Table 2).

\section{Data Collection}

A data collection form was generated by using preprogrammed Excel workbook, available with the WHO/HAI manual (WHO, 2015). Trained data collectors visited the medicine outlets and recorded the medicines' availability by physically checking the stock while documenting the medicine prices. The data collection 
was started in Islamabad and subsequently collected in other regions under the supervision of four authors (AS, HS, ZS, and MS) assigned to specific regions. The data were obtained for $\mathrm{OB}$ and LPG of all the selected 18 CVD medicines. OB refers to the drug product that is sold by the original manufacturer which holds its intellectual property rights, and LPG refers to its lowest priced generic version available at the health facility being surveyed. In Pakistan, public hospitals provide free medicines to the patients, so from these facilities only medicines' availability was recorded, while from private retail pharmacies data for both prices and availability of medicines were gathered.

\section{Data Entry and Analysis}

The data were analyzed by using WHO/HAI preprogrammed workbook, Microsoft Excel, and IBM Statistical Package for the Social Sciences (SPSS) version 22.0. OANDA currency converter was used to convert the local prices to US dollars using the exchange rate on first day of data collection, that is, September 15, 2019 (where 1 USD = 156.56 PKR) (Currency Converter, Foreign Exchange Rates, OANDA, 2020).

\section{Availability}

Medicines' availability was measured as the percentage of medicine outlets where the surveyed medicine was stocked on the day of data collection. WHO recommends that ideally the availability of $80 \%$ or more must be considered optimal for the Essential Medicines (EMs) (WHO, 2015). We described the availability of medicines according to the following criteria, used by many WHO/HAI surveys: <30\%: very low, 30-49\%: low, 50-80\%: fairly high, and >80\%: high (Rathish et al., 2017; Saeed et al., 2019). Associations between availability and other variables were analyzed using the binary logistic regression (available $=1$, unavailable $=0$ ). Beta coefficients with $95 \%$ confidence intervals (CI) were calculated after adjusting for medicine list (global $=0$, supplementary $=1)$, sector $($ public $=$ 0 , private $=1$ ), and brand (originator $=0$, generic $=1$ ) . Multivariate logistic regression was used to estimate the association of key variables with the availability of medicines.

\section{Prices}

The medicine prices were measured as median price ratios (MPRs). The MPR is the ratio of median local unit price of a surveyed medicine to its international reference price (IRP). The supplier IRP of each medicine was obtained from the Management Sciences for Health (MSH) Drug Price Indicator Guide 2015. IRPs represent the procurement prices of multisource drug products offered by non-for-profit suppliers to the LMICs for the multisource products (International Medical Products Price Guide, 2020). According to WHO/HAI methodology, IRPs of a year before the survey should be used for MPR calculation. But the latest available IRPs were published in 2015, so we deflated our prices from 2019 to 2016 by $22 \%$. The deflation factor (i.e., $22 \%$ ) was calculated according to the consumer price indices (CPI) for drugs and medicines of Pakistan from 2016 to 2019 (Pakistan Bureau of Statistics, 2019). Similar to the other studies, this price adjustment method was adopted to make the comparison between local and international prices more reliable (Fang et al., 2013; Alefan et al., 2018; Song et al., 2018). In this study, in a private sector, a medicine's median MPR of more than 5 was considered as excessively priced. This criterion has previously been used by Babar et al. (2007). Although calculating the MPR is a credible method to compare medicine prices among countries, its interpretation still has some ambiguities due to varying medicine components, such as market size, market penetration, medicine pricing mechanisms, scale of economy, and taxation, among different countries. Multiple linear regression (beta coefficients, 95\% CI) was used in the case of MPR (continuous outcome) to analyze associations between the variables (medicine list (global $=0$, supplementary $=1)$ (originator $=0$, generic $=1)$ ) under investigation.

\section{Affordability}

Affordability was measured as the number of day's wages (NDWs) of a lowest paid government worker required to obtain the CVD medicines for a month. The standard treatment with a medicine was considered unaffordable if the patient has to spend more than one day's wage to purchase the treatment for a month, as described by the standard WHO/HAI methodology (WHO, 2015). The calculation of affordability was done using the following formula:

$$
\begin{aligned}
& \text { Number of days'wages required } \\
& =\frac{\text { Median unit price } \times \text { number of units needed per dose } \times 30}{\text { Wage of a lowest paid govt. worker per day }}
\end{aligned}
$$

where the salary of lowest paid government worker is $17,830 \mathrm{PKR}$ (maximum) per month, that is, $594 \mathrm{PKR}$ per day (with effect from July 2019). The affordability of all surveyed medicines was calculated as described in Table 5 .

\section{International Comparison of Affordability}

To enhance the local relevance and international comparability, the medicines were selected according to the following criteria: their inclusion in the NEML, their potential impact on the burden of CVDs, and their frequency of inclusion in surveys by other LMICs. The affordability (NDWs) of OBs and LPGs of four CVD medicines (atenolol $50 \mathrm{mg}$, amlodipine $5 \mathrm{mg}$, captopril $25 \mathrm{mg}$, and simvastatin $20 \mathrm{mg}$ ) from the private sector of Pakistan was compared with affordability of these medicines in six other LMICs (see Table 6). The data on affordability of selected medicines in other LMICs (Afghanistan, Sudan, Lebanon, Egypt, India, and China) was retrieved from the global WHO/ HAI database (World Bank Country and Lending Groups, World Bank Data Help Desk; Health Action International, 2020). Countries such as Afghanistan, Sudan, Lebanon, and Egypt fall under WHO's Eastern Mediterranean Region (EMR) (WHO, 2020b). As Pakistan is also under this region, these countries were used for comparison. Afghanistan also shares a long border with Pakistan, whereas India belongs to South East Asia Region (SEAR) of WHO but it is Pakistan's neighboring country and its medicine pricing and procurement system matches with that of Pakistan. 
TABLE 3 | Regression model examining the effect of sector and medicine types and survey sectors on medicine availability and median price ratio.

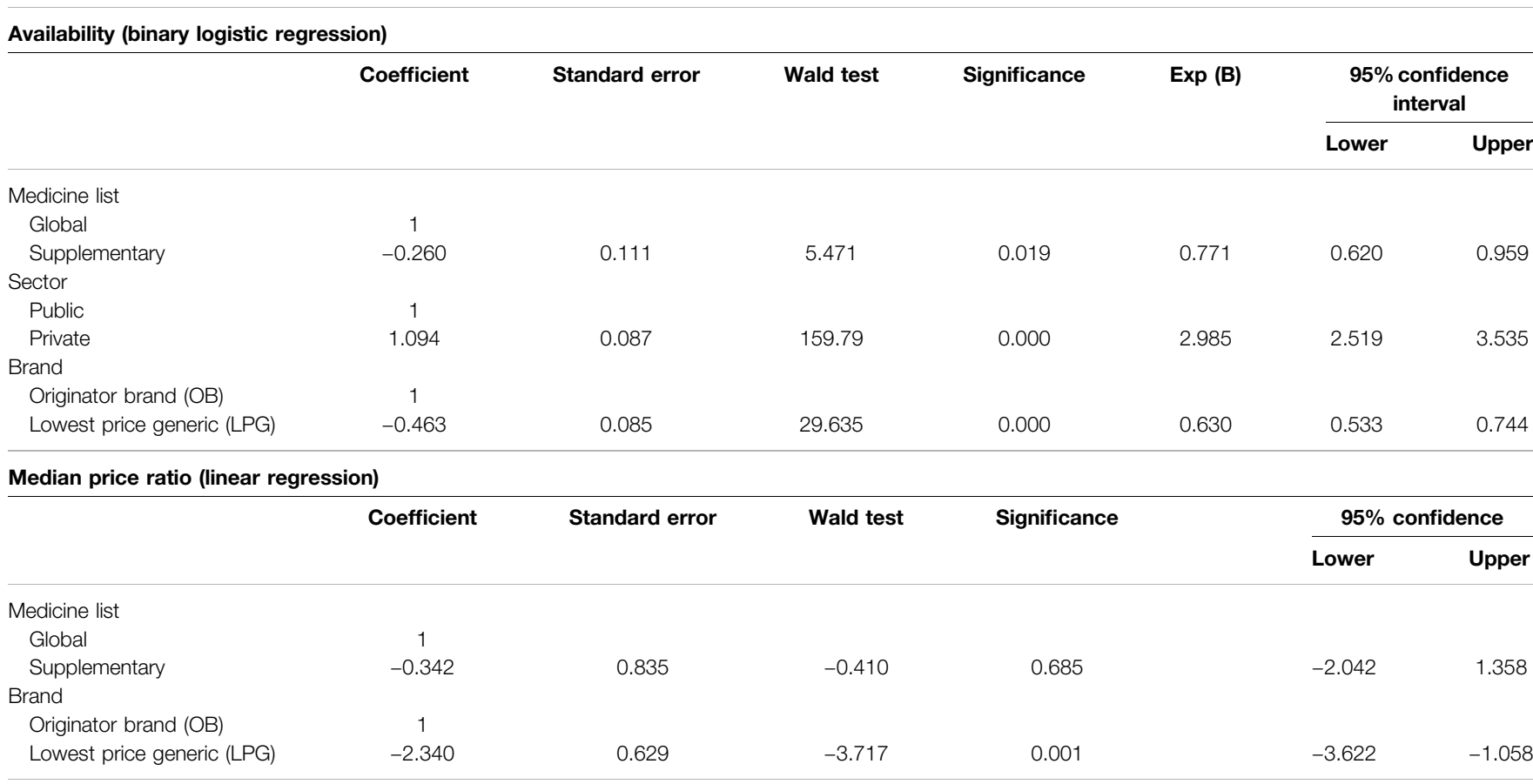

Pakistan also takes India as a reference country while setting the drug prices following external reference pricing mechanism (Drug Regulatory Autority of Pakistan, 2018a; Saeed, 2019). China is another neighbor located at northeastern border of Pakistan. One of the key reasons for selecting these countries for comparison, besides their economic status and geographical location, was the availability of data from the WHO/HAI methodology based surveys conducted in these countries. The latest available surveys were selected for data retrieval. The four selected medicines were most commonly surveyed among all the selected LMICs. Hence these four medicines were used for the comparison.

\section{RESULTS}

\section{Availability of Medicines}

In public sector, the mean availability of both OB and LPG medicines was very poor, that is, only $25.5 \%$ and $30.4 \%$, respectively. The situation was better in private sector, where the mean availability was $34.9 \%$ and $54.6 \%$ for LPGs and OBs, respectively (Supplementary Table S1). The regression analysis further demonstrated that the availability was significantly lower in the public sector as compared to the private sector $(p<0.001)$ (Table 3). Table 4 shows the mean percentage availability of each medicine, along with its categorization into very low, low, fairly high, and high availability, in both public and private sectors. None of the surveyed medicines had ideal availability of $80 \%$ in both public and private sectors. The OBs and LPGs of both lovastatin (5\%) and hydrochlorothiazideHCT $(8 \%)$ were least available in the public sector. In the private sector, the OB HCT was absolutely unavailable and its LPG also had very poor availability (i.e., 25\%). The overall availability of generics was significantly lower than the OBs $(p<0.001)$. The medicines from NEML showed better availability than the supplementary medicines $(p=0.019)$. Inter-regional variations with regards to medicine availability were also evident among the eight surveyed cities, where the public sector of Abbottabad and Peshawar had absolute nonavailability of OBs on the day of data collection. The mean availability of OBs in the public sector ranged from $0 \%$ in Peshawar and Abbottabad to $53 \%$ in Karachi, while that of LPGs in the public sector ranged from $11 \%$ in Peshawar to $52 \%$ in Islamabad. The mean availability of OBs in the private sector ranged from $33 \%$ in AJK to $76 \%$ in Lahore, while that of LPGs in the private sector ranged from $10 \%$ in Quetta to $64 \%$ in both Karachi and Abbottabad (Supplementary Table S2).

\section{Patient Prices in the Private Sector}

The medicine prices which patients had to pay (i.e., out of pocket payments) at private sector retail pharmacies were analyzed in terms of MPRs. For the public sector, the price analysis was not performed because medicines are provided without any charge to the patients. The MPR analysis included medicines with prices found for both types (OB and LPG) in pair (i.e., $n=17$ ) (see Supplementary Table S3). The inflation-adjusted mean MPR was 2.72 and 1 for OBs and LPGs, respectively. In group-wise comparison, as shown in Table 3, the OBs had significantly higher prices than LPGs $(p=0.001)$. The differences between prices of global and supplementary list medicines were insignificant ( $p=0.685)$. Three OBs had MPR above 5 , the set benchmark, and were found excessively overpriced. For OBs, the top five highest MPRs were of lovastatin (7.09), simvastatin (6.48), atorvastatin (5.32), amlodipine (4.68), and atenolol 
TABLE 4 | Individual medicines availability at healthcare facilities.

\begin{tabular}{|c|c|c|c|c|c|}
\hline Medicine Name & Medicine type & $\begin{array}{l}\% \text { Availability in } \\
\text { public sector } \%\end{array}$ & Remarks & $\begin{array}{l}\% \text { Availability in } \\
\text { private sector } \%\end{array}$ & Remarks \\
\hline Acetylsalicylic acid & Originator brand $(\mathrm{OB})$ & 5 & Very low & 25 & Very low \\
\hline Acetylsalicylic acid & Lowest price generic (LPG) & 53 & Fairly high & 65 & Fairly high \\
\hline Amiodarone & $\mathrm{OB}$ & 29 & Very low & 40 & Low \\
\hline Amiodarone & LPG & 29 & Very low & 15 & Very low \\
\hline Amlodipine & OB & 28 & Very low & 78 & Fairly high \\
\hline Amlodipine & LPG & 38 & Low & 58 & Fairly high \\
\hline Atenolol & OB & 40 & Low & 68 & Fairly high \\
\hline Atenolol & LPG & 33 & Low & 63 & Fairly high \\
\hline Atorvastatin & $\mathrm{OB}$ & 36 & Low & 65 & Fairly high \\
\hline Atorvastatin & LPG & 50 & Fairly high & 63 & Fairly high \\
\hline Bisoprolol & $\mathrm{OB}$ & 35 & Low & 68 & Fairly high \\
\hline Bisoprolol & LPG & 23 & Very low & 40 & Low \\
\hline Captopril & $\mathrm{OB}$ & 64 & Fairly high & 80 & High \\
\hline Captopril & LPG & 29 & Very low & 30 & Low \\
\hline Digoxin & $\mathrm{OB}$ & 50 & Fairly high & 60 & Fairly high \\
\hline Digoxin & LPG & 29 & Very low & 10 & Very low \\
\hline Enalapril & $\mathrm{OB}$ & 23 & Very low & 73 & Fairly high \\
\hline Enalapril & LPG & 25 & Very low & 40 & Low \\
\hline Furosemide & $\mathrm{OB}$ & 38 & Low & 73 & Fairly high \\
\hline Furosemide & LPG & 25 & Very low & 18 & Very low \\
\hline Hydrochlorothiazide & $\mathrm{OB}$ & 8 & Very low & 0 & Very low \\
\hline Hydrochlorothiazide & LPG & 8 & Very low & 25 & Very low \\
\hline Losartan & $\mathrm{OB}$ & 7 & Very low & 48 & Low \\
\hline Losartan & LPG & 71 & Fairly high & 58 & Fairly high \\
\hline Lovastatin & OB & 5 & Very low & 10 & Very low \\
\hline Lovastatin & LPG & 5 & Very low & 28 & Very low \\
\hline Methyldopa & $\mathrm{OB}$ & 28 & Very low & 65 & Fairly high \\
\hline Methyldopa & LPG & 33 & Low & 10 & Very low \\
\hline Nifedipine retard & $\mathrm{OB}$ & 21 & Very low & 38 & Low \\
\hline Nifedipine retard & LPG & 29 & Very low & 20 & Very low \\
\hline Propranolol & $\mathrm{OB}$ & 20 & Very low & 68 & Fairly high \\
\hline Propranolol & LPG & 10 & Very low & 23 & Very low \\
\hline Simvastatin & $\mathrm{OB}$ & 14 & Very low & 53 & Fairly high \\
\hline Simvastatin & LPG & 29 & Very low & 43 & Low \\
\hline Spironolactone & $\mathrm{OB}$ & 10 & Very low & 65 & Fairly high \\
\hline Spironolactone & LPG & 33 & Low & 18 & Very low \\
\hline
\end{tabular}

(3.54). The inflation-adjusted MPRs of all LPG medicines were below 5 , indicating tenuous affordability margin. The prices of seven LPG medicines were more than their respective IRPs. These medicines included captopril, with price 1.34 times the IRP, followed by propranolol (1.29), enalapril (1.22), atenolol (1.21), furosemide (1.21), atorvastatin (1.12), and simvastatin (1.12). The individual MPRs of all medicines (both OBs and LPGs) are shown in Figure 1 and Supplementary Table S3.

\section{Affordability}

The specific cardiovascular conditions in which the surveyed medicines can be used are provided in Table 2. Table 5 showed the quantity of each medicine required for 30-day treatment course, median treatment price (MTP), number of days' wages (NDWs) required, and the percentage of cost saved by using LPG instead of $\mathrm{OB}$ to obtain a standard treatment from a specific medicine. Data obtained demonstrated that CVD medicines were unaffordable, NDWs of more than 1, in the private sector with average NDWs of 6.4 and 2.2 for OB and LPG, respectively. Only spironolactone was found affordable with NDWs of 0.8 and 0.4 for both OB and LPG, respectively. Treatment courses with OBs of lovastatin (21.5), amlodipine (14.2), propranolol (12.5), simvastatin (9.8), and atorvastatin (8.1) were among the top five most unaffordable OBs. In case of LPGs, propranolol (5.8), captopril (4.1), furosemide (3.7), nifedipine retard (2.7), and lovastatin (2.5) were ranked higher in the list. We also estimated the cost that can be saved by using generics instead of brands by calculating the percentage difference of MTPs between OBs and LPGs. The results revealed that about $11 \%-88 \%$ of the treatment prices could be saved by switching to LPGs.

\section{International Comparison of Affordability}

The international comparison of the affordability of standard treatment with atenolol, amlodipine, captopril, and simvastatin showed that these drugs were highly unaffordable in Pakistan compared to Sudan, Lebanon, Egypt, India (Delhi), Afghanistan, and China (Shaanxi) (see Table 6). Overall, all four OBs and three out of four LPGs of selected CVD drugs were found highly unaffordable in Pakistan, which is alarming. The NDWs for $\mathrm{OB}$ atenolol were 5.4 in Pakistan and 5.2 in Sudan, while the rest of the countries had NDWs of less than 1 . The OB amlodipine had 


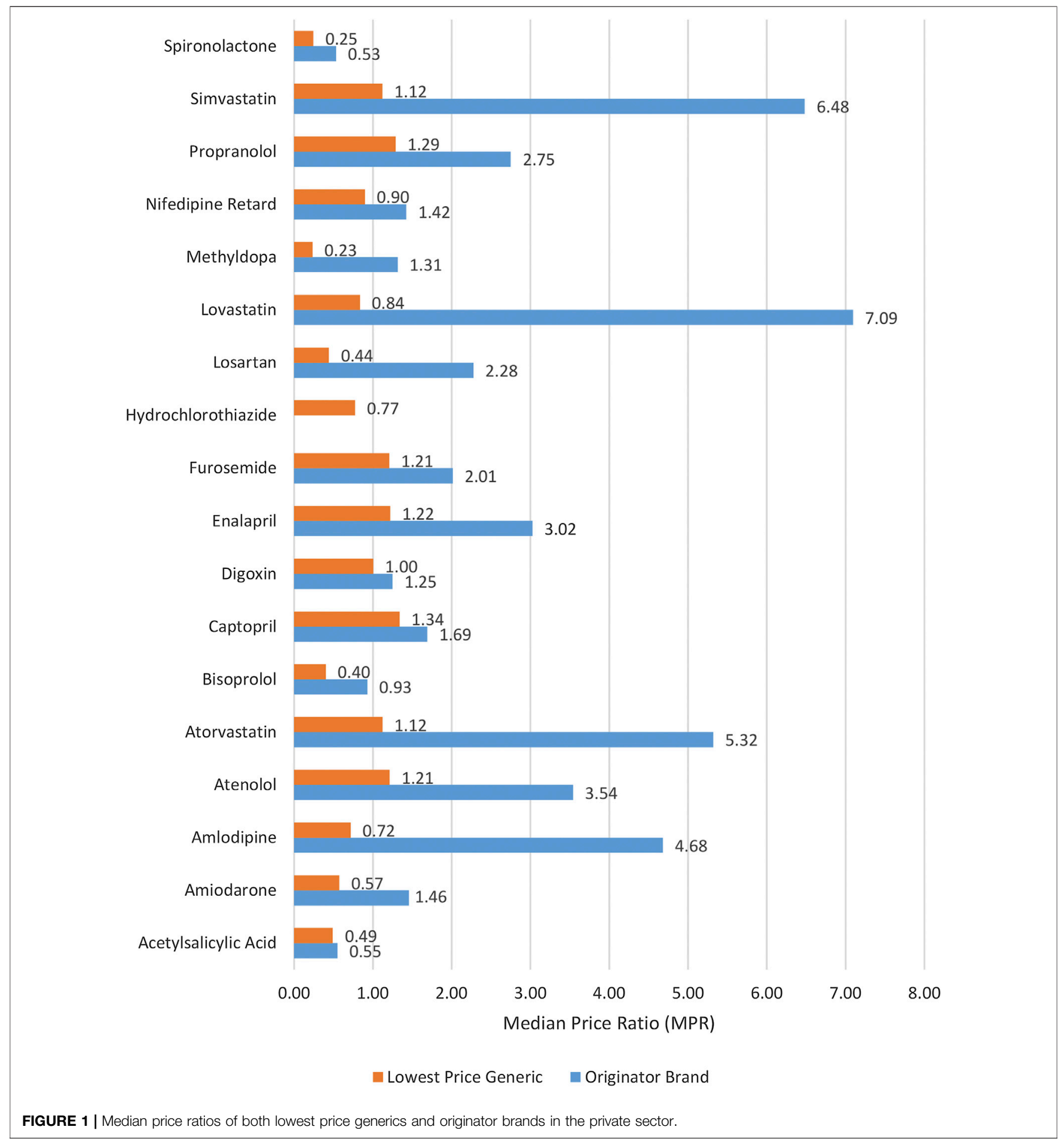

NDWs of more than 1, unaffordable, in Pakistan (14.2), China (3.7), and Egypt (1.7) compared to other countries. The OB captopril was unaffordable in Pakistan (5.1) and Lebanon (1.3) and affordable in Egypt (0.8). OB simvastatin was unaffordable in all countries, ranging from 1.8 in Lebanon to 9.8 in Pakistan. The LPGs atenolol and amlodipine were found unaffordable only in Pakistan (1.8 and 2.2) among all the LMICs included for the comparison. The LPG captopril required the highest NDWs in Pakistan (i.e., 4.1) and was also unaffordable in Sudan (4.2) and India (1.1), while it was affordable in the rest of the LMICs. In case of LPG of simvastatin, it was highly unaffordable in Egypt (2.1), followed by Sudan (2), Pakistan (1.7), and Afghanistan (1.1), yet it was affordable in other LMICs included in the analysis. 
TABLE 5 | Affordability of standard treatments in private retail pharmacies by lowest paid unskilled government worker.

\begin{tabular}{|c|c|c|c|c|c|c|c|}
\hline $\begin{array}{l}\text { Medicine with strength } \\
\text { and dosage form }\end{array}$ & $\begin{array}{l}\text { No. of units } \\
\text { needed per } \\
\text { treatment }\end{array}$ & $\begin{array}{l}\text { Duration of } \\
\text { treatment }\end{array}$ & $\begin{array}{c}\text { Median } \\
\text { treatment } \\
\text { price } \\
\text { (PKR)-OB }\end{array}$ & $\begin{array}{c}\text { Median } \\
\text { treatment } \\
\text { price } \\
\text { (PKR)-LPG }\end{array}$ & $\begin{array}{l}\text { No. of days } \\
\text { wages-OB }\end{array}$ & $\begin{array}{c}\text { No. } \\
\text { of days } \\
\text { wages-LPG }\end{array}$ & $\begin{array}{l}\text { \% Difference between } \\
\text { MTPs of OBs and } \\
\text { LPGs ( } \% \text { of cost } \\
\text { saved by using LPG) }\end{array}$ \\
\hline Acetylsalicylic acid 75 mg tab & 60 & 30 & 986.6 & 881.8 & 1.7 & 1.5 & 10.63 \\
\hline Amiodarone 200 mg tab & 60 & 30 & 2624.8 & 1032.2 & 4.4 & 1.7 & 60.68 \\
\hline Amlodipine 5 mg tab & 60 & 30 & 8427.1 & 1293.8 & 14.2 & 2.2 & 84.65 \\
\hline Atenolol 50 mg tab & 30 & 30 & 3185.6 & 1091.7 & 5.4 & 1.8 & 65.73 \\
\hline Atorvastatin $20 \mathrm{mg}$ cap/tab & 30 & 30 & 4788.0 & 1010.2 & 8.1 & 1.7 & 78.90 \\
\hline Bisoprolol 5 mg cap/tab & 60 & 30 & 1672.1 & 725.0 & 2.8 & 1.2 & 56.64 \\
\hline Captopril 25 mg cap/tab & 60 & 30 & 3042.0 & 2411.3 & 5.1 & 4.1 & 20.73 \\
\hline Digoxin 0.25 mg tab & 30 & 30 & 1124.9 & 903.6 & 1.9 & 1.5 & 19.67 \\
\hline Enalapril 5 mg tab & 30 & 30 & 2720.3 & 1096.9 & 4.6 & 1.8 & 59.67 \\
\hline Furosemide 40 mg cap/tab & 60 & 30 & 3620.5 & 2169.3 & 6.1 & 3.7 & 40.80 \\
\hline $\begin{array}{l}\text { Hydrochlorothiazide } 25 \text { mg } \\
\text { cap/tab }\end{array}$ & 60 & 30 & NA & 1390.1 & 0.0 & 2.3 & \\
\hline Losartan 50 mg cap/tab & 60 & 30 & 4096.8 & 792.9 & 6.9 & 1.3 & 80.64 \\
\hline Lovastatin 20 mg tab & 60 & 30 & 12770.6 & 1503.5 & 21.5 & 2.5 & 88.22 \\
\hline Methyldopa 250 mg tab & 90 & 30 & 3549.0 & 633.8 & 6.0 & 1.1 & 82.14 \\
\hline Nifedipine Retard 20 mg tab & 60 & 30 & 2562.5 & 1618.4 & 4.3 & 2.7 & 36.84 \\
\hline Propranolol 40 mg tab & 90 & 30 & 7419.8 & 3471.8 & 12.5 & 5.8 & 53.20 \\
\hline Simvastatin 20 mg cap/tab & 30 & 30 & 5831.9 & 1008.2 & 9.8 & 1.7 & 82.71 \\
\hline Spironolactone $100 \mathrm{mg}$ tab & 30 & 30 & 478.4 & 220.8 & 0.8 & 0.4 & 53.80 \\
\hline
\end{tabular}

TABLE 6 | International comparison of affordability of standard treatments.

\begin{tabular}{|c|c|c|c|c|c|c|c|c|c|c|c|}
\hline \multirow[t]{2}{*}{ Country } & \multirow[t]{2}{*}{ Survey year } & \multirow[t]{2}{*}{ WB country income group } & \multirow[t]{2}{*}{ WHO region } & \multicolumn{2}{|c|}{$\begin{array}{c}\text { Atenolol } \\
50 \mathrm{mg} \text { tab }\end{array}$} & \multicolumn{2}{|c|}{$\begin{array}{l}\text { Amlodipine } \\
5 \mathrm{mg} \text { tab }\end{array}$} & \multicolumn{2}{|c|}{$\begin{array}{c}\text { Captopril } \\
25 \mathrm{mg} \\
\text { cap/tab }\end{array}$} & \multicolumn{2}{|c|}{$\begin{array}{c}\text { Simvastatin } \\
20 \mathrm{mg}\end{array}$} \\
\hline & & & & $\mathrm{OB}$ & LPG & OB & LPG & OB & LPG & $\mathrm{OB}$ & $\mathrm{LPG}$ \\
\hline Pakistan & 2019 & LMI & EMR & 5.4 & 1.8 & 14.2 & 2.2 & 5.1 & 4.1 & 9.8 & 1.7 \\
\hline Sudan & 2013 & LMI & EMR & 5.2 & 0.5 & NA & 0.8 & NA & 3.2 & NA & 2 \\
\hline Lebanon & 2013 & UMl & EMR & 0.7 & 0.2 & 1 & 0.7 & 1.3 & 0.7 & 1.8 & 0.3 \\
\hline Egypt & 2013 & LMI & EMR & 0.4 & 0.1 & 1.7 & 0.6 & 0.8 & 0.5 & 4.3 & 2.1 \\
\hline India & 2011 & LMl & SEAR & 0.4 & 0.4 & 1 & 0.3 & NA & 1.1 & 2.2 & 0.6 \\
\hline Afghanistan & 2011 & LI & EMR & NA & 0.2 & NA & NA & NA & 0.4 & NA & 1.1 \\
\hline China & 2014 & UMI & WPR & NA & NA & 3.7 & 0.8 & NA & NA & 2.6 & 1.3 \\
\hline
\end{tabular}

WB, World Bank; LMI, Lower Middle Income; UMI, Upper Middle Income; LI, Low Income; EMR, Eastern Mediterranean Region; SEAR, South East Asia Region; WPR, Western Pacific Region.

\section{DISCUSSION}

The results of this study underpinned the urgency to improve the availability of medicines for CVDs, particularly in the public sector. This is vital to ensure that the prescribed CVD medicines are available and affordable. It was surprising to see that none of the surveyed medicines met the ideal availability benchmark of $80 \%$ in both public and private sectors. Although these medicines are provided free of charge to the patients in the public sector, low availability (i.e., only $28 \%$ ) compels the patients to purchase the medicines from the private sector. However, the availability at private retail pharmacies was also not up to the mark; that is, only $45 \%$ of the pharmacies had the surveyed medicines available on the day of data collection. The standard treatment affordability calculation in the private sector revealed that both OBs and LPGs of all selected medicines were not affordable for a lowest paid unskilled government employee. It should also be noted that about a quarter of Pakistan's population (i.e., 46 million) lives below the national poverty line and $4.5 \%$ of the people are unemployed, while those who are employed earn far less than the daily wage of a lowest paid government worker, which was used for treatment affordability calculation (Poverty and Equity Data Portal, 2020). In Pakistan, for everybody, access to public hospitals is almost free, with a paltry fee of rupees $20 /$-PKR (0.13USD), not limited to one consultation, where free medicines are provided after the consultation. However, for major surgeries and laboratory investigations, patients have to pay out of pocket. In private sector hospitals and pharmacies, the patients are supposed to pay for medical care including medicines. In 2016, in eight cities of Pakistan, a micro health insurance 
program was launched for the underprivileged citizens who intend to get treatment from private hospitals. So far, the program included 57 cities and enrolled approximately 7 million families, until February 2020. Although this is a good initiative by the Government of Pakistan, it does not specifically cover the medication cost incurred upon the patients. Besides, there is no particular financing scheme in place for the vast majority of the population who belong to middle income families and could hardly make their both ends meet. There is also lack of financial protection for the patients who obtain medicines from retail pharmacies.

According to our data, in the public sector, the LPGs had better availability than OBs; conversely, in the private sector, the availability of OBs was higher than that of LPGs. Since the overall availability was better in the private sector, it would be reasonable to interpret that patients had to purchase expensive OBs in most cases, compromising the affordability of patients. As the use of generic medicines can improve affordability for the masses, this also shows the need and potential to improve understanding of generic medicines in Pakistan's healthcare sector (Babar et al., 2007; Jamshed et al., 2009; Jamshed et al., 2011).

Similar trend regarding the availability of essential medicines was observed in previous surveys conducted in Lahore division of Pakistan, in 2016-17 and 2019 (Saeed et al., 2019; Saeed et al., 2020). There could be many reasons behind the poor availability of medicines, such as poor estimation of demands, delays in receiving the medication orders, and budgetary constraints. However, further in-house inspections are needed to determine the specific causes of poor availability. HCT was either unavailable or poorly available at both public and private health facilities, corroborating our previous study (Saeed et al., 2019) and a previous report on the availability of essential drugs, particularly HCTZ, for chronic diseases in six low and middle income countries including Bangladesh, Nepal, and Pakistan (Mendis et al., 2005). Furthermore, the poor availability of HCTZ can be attributed to the prescribing trends, as evident by a study from Karachi, Pakistan, suggesting that, among all the treatment options, thiazides were hardly prescribed to the patients, whereas beta blockers and angiotensin converting enzyme inhibitors were used more frequently. This could possibly explain the reason behind poor availability of HCT (Hussain et al., 2015).

Overall, the essential medicines listed in the National Essential Medicines List had better availability than the medicines listed in the supplementary list. Bazargani et al. did a secondary analysis of medicine's availability in the public and private sectors of 23 countries including surveys conducted utilizing WHO/HAI methodology. While doing this analysis, they categorized the medicines into essential and non-essential (not included into the NEML) and found that the availability of both types of medicines was suboptimal but the essential medicines had better availability than the non-essential medicines, corroborating our findings (Bazargani et al., 2014). Besides, the inter-regional comparison on medicine availability showed that OBs were more available in Karachi and Lahore. This could be due to better purchasing power and better economy of these big cities.
Moreover, these cities are nerve centers of many multinational pharmaceutical companies; in addition, their offices and manufacturing units are based here too. Peshawar had relatively poor availability of selected medicines among all provincial capitals. The possible reason could be its relatively poor economy.

While doing the pricing analysis, only those medicines were included which had both OBs and LPGs available in the private sector. HCT was excluded as its $\mathrm{OB}$ was not available. This analysis was limited to the private sector only, because in the public sector, medicines are provided free of charge to the patients. The results revealed that the prices of selected CVD medicines were moderate to high in Pakistan, as the overall prices ranged from 0.23 to 7.09 times their respective IRPs. As expected, the regression analysis showed that the LPGs prices were lower than the OBs. A subsample of three $\mathrm{OB}$ medicines was highly expensive relative to the IRP. Seven LPG medicines were moderately expensive relative to the IRP, out of which, one LPG medicine (propranolol) exhibited substantial variation in unit price across the retail pharmacies, warranting further research to investigate reasons behind this variation. In Pakistan, in most cases the unit price of a medicine remained within a narrow range, probably because the maximum retail prices are fixed by the drug regulatory authority of Pakistan (DRAP) and also due to strong competition in domestic market. Moreover, the inspections by drug inspectors who are appointed by the government of Pakistan (responsible for monitoring of adherence to pricing policies by the retailers, distributors, and manufacturers) might have worked in this regard; nonetheless, they seldom monitor the stock control and inventory for both the OBs and the LPGs, which is purely driven by the prescribing trends.

Affordability of CVD medicines was also calculated in the private sector for both OB and LPG. The affordability calculation was made by considering number of days a lowest paid government worker would have to work in a month, for obtaining a standard course of treatment of a medicine. The results showed that treatment with both OBs and LPGs of CVD medicines were unaffordable. A study from Bangladesh also reported that CVD medicines were among most unaffordable essential medicines (Kasonde et al., 2019). OBs and LPGs of all drugs except one (spironolactone) were found to be unaffordable. In Pakistan, OOP expenditures are around $70 \%$ of the total healthcare expenditures. Not only are CVDs the most prevalent diseases among South Asian population, but also being a South Asian is considered a risk factor for CVD (Lozano et al., 2012; Khalid and Sattar, 2016). In this context, our data suggested that probably many CVD patients, especially living in poverty struck rural areas, had to forego the treatments, considering the extent of unaffordability of CVD medicines observed in this study. This could perhaps further lead to increase in CVD-related morbidity and mortality in Pakistan.

We also calculated the percentage difference between standard treatment prices of OBs and LPGs to estimate the cost savings after switching from OBs to generics. It was found that $11 \%-88 \%$ of the treatment price could be saved by switching from OBs to generics. This highlights the significance and need of generic 
prescribing, which could be one of the best possible solutions to reduce patient's OOP expenditures (Dixit et al., 2018).

The affordability of standard treatment with four CVD drugs in Pakistan was compared with that of six other LMICs. The LPGs were affordable in most of the countries, while OBs were unaffordable in most of the regions. The international comparison on the affordability of medicines suggested that the treatment for CVDs is markedly unaffordable in Pakistan, both OBs and LPGs of selected CVD medicines, compared to the other six LMICs. However, the small sample size of CVD medicines for this comparison limits the generalizability of the results.

There could be several implications for policy makers that are needed to be considered while devising medicine pricing policies. NEML-based procurement system must be ensured at least in public sector hospitals. Rules must be devised to maintain a minimum stock level of essential medicines in the private sector as well. Keeping in view the high prevalence of chronic diseases such as CVDs and diabetes, the NEML could be bifurcated into main groups of medicines (i.e., medicines for chronic and acute diseases). It should be also mandated for every public sector hospital to procure certain number of medicines from both groups. This could help improving the availability of medicines for chronic diseases. Moreover, generic prescribing must be mandated to reduce the burden on patients' pocket. But there could be several limitations in the implementation of generic prescribing in Pakistan's healthcare settings. There are no regulations that prohibit a pharmacist from substituting branded drugs with generic drugs but like many other LMICs, high perverse incentives from the multinational companies along with pressure from medical representatives lead to malpractice of brand drug prescribing and dispensing (Jamshed et al., 2012). A study conducted in Peshawar, Pakistan, reported a very high number of brands in the prescriptions, as compared to generics, indicating brand prescribing monopoly patronized by the doctors, co-influenced by pharmaceutical companies due to overt promotion of their brands knowledge (Raza et al., 2014). Another study conducted in Lahore, Pakistan, reported that the majority of the medical and pharmacy students had doubts on the bioequivalence of generic drugs to their respective OBs. These issues highlight the pressing need for training of medical and pharmacy students, practitioners, and pharmacists regarding dispensing and prescribing of generic drugs. Besides, interventions should be made to educate the public about availability, efficacy, and cost effectiveness of generic drugs (Asif et al., 2018). Innovative financing mechanisms that support the sale of essential medicines for chronic diseases at private retail pharmacies must be introduced.

Mechanism for regular monitoring and reporting of availability and prices of essential medicines must be devised. The drug inspectors or a third party regulator could be given the responsibility of monitoring the medicine price and availability. A mobile application, "WHO Essential Medicines and Health Products Price and Availability Monitoring (WHO EMP MedMon)" developed by WHO, could also be used for pricing data collection and analysis. This application is based on standard
WHO/HAI methodology (WHO, 2019). The local production of essential medicines for chronic diseases must be promoted by subsidizing raw material. Implementation of differential pricing mechanism and tax exemptions for essential medicines could be one of the rational options. The medicines and public sector hospitals could be partially subsidized while giving priority to the medicines used for chronic/most prevalent diseases. Pakistan should also learn from the pricing strategies being employed by other LMICs.

Our study also had some limitations as follows: only those CVD medicines were included in the survey which had Management Sciences for Health International Reference Prices (MSH IRP) available. This is for the sake of MPR calculation, as required by standard WHO/HAI methodology. This means that medicines with specific strength and dosage form were included. This could have resulted in underestimation of the availability of some medicines because the surveyed facility could have stocked the other dosage form or strengths of the surveyed medicines on the day of data collection. The MPRs were calculated in this study by using 2015 MSH IRPs because the latest MSH IRPs were not available. However, we have deflated the prices using the CPI in order to make the MPR calculation reliable. To resolve this issue, the HAI experts suggest avoiding calculating it and rely on median unit prices (MUPs) only. So, we have also calculated and presented the MUPs. The affordability calculations were made for each medicine separately, whereas most of the patients with chronic diseases have co-morbid conditions that require multiple medications at a time. This would further increase the number of CVD patients who could not afford these medicines. It is a cross-sectional study and does not reflect the long-term availability and affordability of medicines. So, there is a need to perform longitudinal studies in this regard. Since the study regions and medicine outlets were selected on the basis of $\mathrm{WHO} /$ HAI methodology, most of the major cities in Pakistan got selected from each province. Nonetheless, only a few rural and peri-urban medicine outlets were surveyed, limiting the generalizability of results to rural regions. Lastly, the international comparison of medicines affordability in Pakistan with that of other LMICs included the surveys which were a few years apart. This might have affected the reliability of the comparison. However, it does provide a useful evidence to the policy makers about the difference of affordability of CVD medicines in these countries.

\section{CONCLUSION}

Our study has shown poor availability of CVD medicines in public sector hospitals, forcing the patients to pay out of pocket for the purchase of medicines from private sector retail pharmacies. Although the availability of medicines was better in the private sector, it was below the standard benchmark defined by WHO. When compared to IRPs, the OBs were found to be high priced in case of a number of medicines. However, the prices of LPGs were somewhat reasonable in private sector retail pharmacies necessitating to further improve the use of generic medicines. The standard courses of treatment with both the OBs and LPGs were not affordable for a lowest paid unskilled government worker. Overall, the majority of 
the selected CVD medicines were found quite unaffordable in Pakistan when compared with other LMICs. Among possible solutions, the implementation of generic prescribing is imperative. Moreover, policies should be devised to enforce NEML-based procurement system, promote the local production of CVD medicines and regular and systematic monitoring of medicines' prices and availability, implement generic prescribing and dispensing, and encourage regular research in this area.

\section{DATA AVAILABILITY STATEMENT}

The raw data supporting the conclusions of this article will be made available by the authors, without undue reservation.

\section{ETHICS STATEMENT}

Ethics approval was obtained from the Medical Ethics Cimmittee, Xi'an, Jiao tong University, China, under the study ID 2019-0162, and the research ethics committee, department of pharmacy practice, faculty of pharmacy, The University of Lahore, Pakistan under study ID REC-DPP/FOP/8A. The study did not include any identifiable human or animal data.

\section{AUTHOR CONTRIBUTIONS}

AS, ZB, and YF conceptualize the study. ZS, HS, AS, and ZB designed methodology. ZS, HS, and AS trained the data collectors

\section{REFERENCES}

Alefan, Q., Amairi, R., and Tawalbeh, S. (2018). Availability, prices and affordability of selected essential medicines in Jordan: a national survey. BMC Health Serv. Res. 18, 787. doi:10.1186/s12913-018-3593-9

Asif, U., Saleem, Z., Yousaf, M., Saeed, H., Hashmi, F. K., and Hassali, M. A. (2018). Exploring the knowledge and attitude of medical and pharmacy students about generic medicine in Lahore, Pakistan. J. Generic Med. 14 (1), 22-28. doi:10. $1177 / 1741134317748344$

Babar, Z. U., Ibrahim, M. I., Singh, H., Bukahri, N. I., and Creese, A. (2007). Evaluating drug prices, availability, affordability, and price components: implications for access to drugs in Malaysia. PLoS Med. 4, e82. doi:10.1371/ journal.pmed.0040082

Bazargani, Y. T., Ewen, M., De Boer, A., Leufkens, H. G., and Mantel-Teeuwisse, A. K. (2014). Essential medicines are more available than other medicines around the globe. PLoS One 9, e87576. doi:10.1371/journal.pone.0087576

Beran, D., Perrin, C., Billo, N., and Yudkin, J. S. (2014). Improving global access to medicines for non-communicable diseases. Lancet Glob Health 2, e561-e562. doi:10.1016/s2214-109x(14)70189-5

Buabeng, K. O., Matowe, L., and Plange-Rhule, J. (2004). Unaffordable drug prices: the major cause of non-compliance with hypertension medication in Ghana. J. Pharm. Pharmaceut. Sci. 7, 350-352. Available at: https:/europepmc.org/ article/med/15576016 (Accessed June 25, 2020).

Calvo-Vargas, C. G., Parra Carrillo, J. Z., Grover Páez, F., and Fonseca Reyes, S. (1998). Changes in the costs of antihypertensive medications in a developing country: a study in Mexico comparing 1990 and 1996. Am. J. Hypertens 11, 487-493. doi:10.1016/S0895-7061(97)00459-7 and obtained the data. YF provided resources and supervised the project. ZS, FS, MS, and SG worked as survey area managers. $\mathrm{MA}, \mathrm{AG}, \mathrm{KL}$, and $\mathrm{KH}$ did data cleaning, validation, and entry. AS, HS, CY, and MJ analyzed the data. AS and HS wrote original draft. YF, ZB, ZS, CY, JC, and WJ reviewed and edited the manuscript.

\section{FUNDING}

This work was funded by the "Young Talent Support Plan," "High Achiever Plan" of Health Science Center, Xi'an Jiaotong University, and the Central University Basic Research Fund (2015qngz05).

\section{ACKNOWLEDGMENTS}

The authors are thankful to Dr. Margaret Ewen, senior projects manager, medicine prices at Health Action International (HAI), for helping them in designing the study. They would like to acknowledge the pharmacists from surveyed institutions, data collectors, and partners from research area who made this research possible.

\section{SUPPLEMENTARY MATERIAL}

The Supplementary Material for this article can be found online at: https://www.frontiersin.org/articles/10.3389/fphar.2020.595008/ full\#supplementary-material.

Currency Converter (2020). Currency converter, foreign exchange rates, OANDA. Available at: https://www1.oanda.com/currency/converter/ (Accessed June 25, 2020).

De Tole̊do Nóbrega, O., Marques, A. R., De Araújo, A. C. G., De Oliveira Karnikowski, M. G., De Oliveira Silva Naves, J., et al. (2007). Retail prices of essential drugs in Brazil: an international comparison. Rev. Panam. Salud Publica/Pan Am. J. Public Heal. 22, 118-123. doi:10.1590/s1020-49892007000700006

Dixit, A., Kumar, N., and Kumar, S. (2018). Use of generic medicines. J. Health Manag. 20, 84-90. doi:10.1177/0972063417747747

Drug Regulatory Authority of Pakistan (2018a). Drug pricing policy 2018. Available at: http://www.dra.gov.pk/userfiles1/file/Drug Pricing Policy 2015.pdf.

Drug Regulatory Authority of Pakistan (2018b). National essential medicines list. Fang, Y., Wagner, A. K., Yang, S., Jiang, M., Zhang, F., and Ross-Degnan, D. (2013). Access to affordable medicines after health reform: evidence from two crosssectional surveys in Shaanxi Province, western China. Lancet Glob. Health 1, e227. doi:10.1016/S2214-109X(13)70072-X

Finance Division, Government of Pakistan (2020). Available at: http://www. finance.gov.pk/ (Accessed June 25, 2020).

Health Action International (2020). Medicine prices, availability, affordability \& price components database. Available at: https://haiweb.org/what-we-do/priceavailability-affordability/price-availability-data/ (Accessed June 25, 2020).

Hsu, J., Flores, G., Evans, D., Mills, A., and Hanson, K. (2018). Measuring financial protection against catastrophic health expenditures: methodological challenges for global monitoring. Int. J. Equity Health 17, 69. doi:10.1186/s12939-018-0749-5

Hussain, I. M., Naqvi, B. S., Qasim, R. M., and Ali, N. (2015). Current trends in treatment of hypertension in Karachi and cost minimization possibilities. Pak. J. Med. Sci. 31 (5), 1021. doi:10.12669/pjms.315.7438 
International Medical Products Price Guide (2020). Management sciences for health. Available at: https://www.msh.org/resources/international-medicalproducts-price-guide?keywords=medicine pricing (Accessed June 25, 2020).

Jafar, T. H., Haaland, B. A., Rahman, A., Razzak, J. A., Bilger, M., Naghavi, M., et al. (2013). Non-communicable diseases and injuries in Pakistan: strategic priorities. Lancet 381, 2281-2290. doi:10.1016/S0140-6736(13)60646-7

Jamshed, S. Q., Babar, Z. U., Ibrahim, M. I., and Hassali, M. A. (2009). Generic medicines as a way to improve access and affordability: a proposed framework for Pakistan. J. Clin. Diagn. Res. 3 (3), 1596-600.

Jamshed, S. Q., Hassali, M. A., Ibrahim, M. I., and Babar, Z. U. (2011). Knowledge attitude and perception of dispensing doctors regarding generic medicines in Karachi, Pakistan: a qualitative study. J. Pak. Med. Assoc. 61 (1), 80-83.

Jamshed, S. Q., Ibrahim, M. I., Hassali, M. A., Masood, I., Low, B. Y., and Shafie, A. A. (2012). Perception and attitude of general practitioners regarding generic medicines in Karachi, Pakistan: A questionnaire based study. South Med. Rev. 5 (1), 22.

Kasonde, L., Tordrup, D., Naheed, A., Zeng, W., Ahmed, S., and Babar, Z. U. D. (2019). Evaluating medicine prices, availability and affordability in Bangladesh using World Health Organisation and health action international methodology. BMC Health Serv. Res. 19, 383. doi:10.1186/s12913-019-4221-z

Khan, S. A. (2019). Situation Analysis of Health Care System of Pakistan: Post 18 Amendments. Health Care Curr. Rev. 7, 244. doi:10.35248/2375-4273.19.07.244

Khalid, M., and Sattar, A. (2016). Households study on out-of-pocket health expenditures in Pakistan. Forman J. Econ. Stud. 12, 75-88. doi:10.32368/fjes. 20161205

Khatib, R., McKee, M., Shannon, H., Chow, C., Rangarajan, S., Teo, K., et al. (2016). Availability and affordability of cardiovascular disease medicines and their effect on use in high-income, middle-income, and low-income countries: an analysis of the PURE study data. Lancet 387, 61-69. doi:10.1016/S01406736(15)00469-9

Kiani, A., Qadeer, A., Mirza, Z., Khanum, A., Tisocki, K., and Mustafa, T. (2006). Prices, availability and affordability of medicines in Pakistan. Available at: https://haiweb.org/wp-content/uploads/2015/07/Pakistan-Report-PricingSurveys.pdf.

Lozano, R., Naghavi, M., Foreman, K., Lim, S., Shibuya, K., Aboyans, V., et al. (2012). Global and regional mortality from 235 causes of death for 20 age groups in 1990 and 2010: a systematic analysis for the Global Burden of Disease Study 2010. Lancet 380, 2095-2128. doi:10.1016/S0140-6736(12)61728-0

Mendis, S., Abegunde, D., Yusuf, S., Ebrahim, S., Shaper, G., Ghannem, H., et al. (2005). WHO study on prevention of REcurrences of myocardial infarction and StrokE (WHO-PREMISE). Bull. World Health Organ. 83, 820-829. doi:/S004296862005001100011

Murray, C. J. L., and Lopez, A. D. (2017). Measuring global health: motivation and evolution of the Global Burden of Disease Study. Lancet 390, 1460-1464. doi:10. 1016/S0140-6736(17)32367-X

Pakistan Bureau of Statistics (2019). Monthly review on price indices.

Pakistan Country Report-Sustainable Development Goals. (2017). Available at: https://www.sdgpakistan.pk/uploads/pub/SDGs_Annual_Progress_Report_ 2017.pdf (Accessed December 31, 2020).

Penchansky, R., and Thomas, J. W. (1981). The concept of access: definition and relationship to consumer satisfaction. Med. Care 19, 127-140. doi:10.1097/ 00005650-198102000-00001

Population Pakistan Bureau of Statistics (2020). Available at: http://www.pbs.gov. $\mathrm{pk}$ /population-tables (Accessed June 25, 2020).

Quick, J. D., Hogerzeil, H. V., Vela'squez, G., and Rago, L. (2002). Twenty-five years of essential medicines. Bull. World Health Organ. 80, 913-914.

Rathish, D., Premarathna, I., Jayathilake, T., Kandegedara, C., Punchihewa, K., Ananda, L., et al. (2017). Availability of essential medicines in selected public, primary and secondary health care institutions of a rural Sri Lankan district: a spot survey. BMC Health Serv. Res. 17, 11. doi:10.1186/s12913-016-1969-2

Raza, U. A., Khursheed, T., Irfan, M., Abbas, M., and Irfan, U. M. (2014). Prescription patterns of general practitioners in Peshawar, Pakistan. Pak. J. Med. Sci. 30 (3), 462. doi:10.12669/pjms.303.4931
Sachs, J. D., and McArthur, J. W. (2005). The millennium project: a plan for meeting the millennium development goals. Lancet 365 (9456), 347-53. doi:10. 1016/s0140-6736(05)17791-5

Saeed, A. (2019). "External reference pricing and medicines," in Encyclopedia of pharmacy practice and clinical pharmacy. Editor Z.-U.-D. Babar (Oxford, United Kingdom: Elsevier), 299-308.

Saeed, A., Saeed, H., Saleem, Z., Fang, Y., and Babar, Z.-U.-D. (2019). Evaluation of prices, availability and affordability of essential medicines in Lahore Division, Pakistan: a cross-sectional survey using WHO/HAI methodology. PLoS One 14, e0216122. doi:10.1371/journal.pone.0216122

Saeed, A., Saeed, H., Saleem, Z, Yang, C., Jiang, M., Zhao, M., et al. (2020). Impact of National Drug Pricing Policy 2018 on access to medicines in Lahore division, Pakistan: a pre-post survey study using WHO/HAI methodology. BMJ Open 10 (10), e034720. doi:10.1136/bmjopen-2019-034720

Song, Y., Bian, Y., and Zhen, T. (2018). Making medicines more accessible in China: an empirical study investigating the early progress of essential medicine system. PLoS One 13. doi:10.1371/journal.pone.0201582

van Mourik, M. S., Cameron, A., Ewen, M., and Laing, R. O. (2010). Availability, price and affordability of cardiovascular medicines: a comparison across 36 countries using WHO/HAI data. BMC Cardiovasc. Disord. 10, 25. doi:10.1186/ 1471-2261-10-25

WHO (2011). Global status report on noncommunicable diseases 2010. Available at: http://www.who.int/nmh/publications/ncd_report2010/en/ (Accessed June $25,2020)$.

WHO (2013). Global Action plan for the prevention and control of NCDs 2013-2020. Available at: http://www.who.int/nmh/events/ncd_action_plan/ en/ (Accessed June 25, 2020).

WHO (2015). Measuring medicine prices, availability, affordability and price components. Available at: http://www.who.int/medicines/areas/access/ medicines_prices08/en/ (Accessed June 25, 2020).

WHO (2019). MedMon - WHO essential medicines and health products price and availability monitoring mobile application. Available at: http://www.who.int/ medicines/areas/policy/monitoring/empmedmon/en/ (Accessed June 26, 2020).

WHO (2020a). About cardiovascular diseases. Available at: https://www.who.int/ cardiovascular_diseases/about_cvd/en/ (Accessed June 25, 2020).

WHO (2020b). Regional offices. World Health Organisation. Available at: https:// www.who.int/about/who-we-are/regional-offices (Accessed June 26, 2020).

Wirtz, V. J., Kaplan, W. A., Kwan, G. F., and Laing, R. O. (2016). Access to medications for cardiovascular diseases in low- and middle-income countries. Circulation 133, 2076-2085. doi:10.1161/CIRCULATIONAHA.115.008722

World Bank Data Help Desk (2020). Country and lending groups - World Bank data help Desk. Available at: https://datahelpdesk.worldbank.org/ knowledgebase/articles/906519-world-bank-country-and-lending-groups (Accessed June 25, 2020).

World Bank Publ (2020). Poverty \& equity data portal World Bank Publ. Available at: http://povertydata.worldbank.org/poverty/home/ (Accessed June 26, 2020).

Zaidi, S., Bigdeli, M., Aleem, N., and Rashidian, A. (2013). Access to essential medicines in Pakistan: policy and health systems research concerns. PloS one 8 (5), e63515. doi:10.1371/journal.pone.0063515

Conflict of Interest: The authors declare that the research was conducted in the absence of any commercial or financial relationships that could be construed as a potential conflict of interest.

Copyright $\odot 2021$ Saeed, Saeed, Saeed, Saleem, Yang, Chang, Jiang, Zhao, Saqlain, Ji, Aziz, Lambojon, Gillani, Hayat, Gul, Fang and Babar. This is an open-access article distributed under the terms of the Creative Commons Attribution License (CC $B Y)$. The use, distribution or reproduction in other forums is permitted, provided the original author(s) and the copyright owner(s) are credited and that the original publication in this journal is cited, in accordance with accepted academic practice. No use, distribution or reproduction is permitted which does not comply with these terms. 